\title{
Imaging Spectroscopy of Urban Environments
}

\author{
S. van der Linden ${ }^{1,2}$ (D) A. Okujeni ${ }^{1} \cdot$ F. Canters ${ }^{3} \cdot$ J. Degerickx ${ }^{4} \cdot$ U. Heiden ${ }^{5}$. \\ P. Hostert ${ }^{1,2} \cdot$ F. Priem ${ }^{3} \cdot$ B. Somers ${ }^{4} \cdot$ F. Thiel ${ }^{1}$
}

Received: 2 October 2017 / Accepted: 5 July 2018

(c) Springer Nature B.V. 2018

\begin{abstract}
Future spaceborne imaging spectroscopy data will offer new possibilities for mapping ecosystems globally, including urban environments. The high spectral information content of such data is expected to improve accuracies and thematic detail of maps on urban composition and urban environmental condition. This way, urgently needed information for environmental models will be provided, for example, for microclimate or hydrological models. The diverse vertical structures, highly frequent spatial change and a great variety of materials cause challenges for urban environmental mapping with Earth observation data, especially at the $30 \mathrm{~m}$ spatial resolution of data from future spaceborne imaging spectrometers. This paper gives an overview of the state-of-the-art in urban imaging spectroscopy considering decreasing spatial resolution, the related user requirements and existing knowledge gaps, as well as expected future directions for the work with new data sets.
\end{abstract}

Keywords Imaging spectroscopy · Hyperspectral · Urban · Unmixing · Spatial resolution · Environmental Mapping and Analysis Program (EnMAP)

\section{Introduction}

In $2018,55 \%$ of the world's population is estimated to live in cities and the numbers of urban dwellers and of mega cities will continue to increase rapidly (UN 2018). The twenty-first century is therefore referred to as the Century of the City (Seto et al. 2010).

S. van der Linden

sebastian.linden@geo.hu-berlin.de

1 Geography Department, Humboldt-Universität zu Berlin, Unter den Linden 6, 10099 Berlin, Germany

2 Integrative Research Institute on Transformations of Human-Environment Systems, HumboldtUniversität zu Berlin, Unter den Linden 6, 10099 Berlin, Germany

3 Department of Geography, Cartography and GIS Research Group, Vrije Universiteit Brussel, Pleinlaan 2, 1050 Brussels, Belgium

4 Division of Forest, Nature and Landscape, KU Leuven, Celestijnenlaan 200e, 3001 Leuven, Belgium

5 Department of Land Surface Dynamics, German Remote Sensing Data Center, German Aerospace Center, Münchner Str. 20, 82234 Weßling, Germany 
Urbanization constitutes a demographic, socioeconomic and biophysical process that substantially contributes to global environmental change (Lambin et al. 2001; Pickett et al. 2011). The expansion of impervious areas, the loss of natural environments as well as the increased landscape fragmentation along with the concentration of human consumption, production and waste generation alter biogeochemical cycles, climate regimes, hydrological systems and biodiversity at multiple scales (Grimm et al. 2008; Lawler et al. 2014). Globally, urban areas are a major source of $\mathrm{CO}_{2}$ and other greenhouse gas emissions (Kennedy et al. 2009). At the regional and local scale, cities are characterized by the urban heat island, that is, an increased air temperature (Grimmond 2007; Oke 1982), and by air pollution (Fenger 1999; Hatt et al. 2004). Urban ecosystem condition, its functioning and spatial-temporal change influence the quality of life and human health (Harlan et al. 2006; Pauleit et al. 2005; Tan et al. 2010). At the same time, contemporary urbanization has the chance to promote ecological sustainability due to increased environmental awareness and returns from innovation, productivity and efficiency (Grimm et al. 2008; Seto et al. 2010). To ensure that policy sustains benefits of urbanization and anticipates or manages the negative consequences of urban growth (UN-Habitat 2010), the interactions between socioeconomic and environmental processes in urban landscapes need to be better understood (Alberti 2005). Integrated research targeting the diverse aspects and implications of urban systems in times of rapid urbanization is of great importance to face the complexity of urban dynamics.

Remote sensing can contribute in many ways to the analysis of urban environments and provides substantial information on ecosystem characteristics (see Small et al. 2018 for a general overview on urban remote sensing). We define the term urban environment in this paper as contiguous areas of anthropogenic, artificial surfaces used for transport, commerce, production, administration or housing, plus the included or adjacent vegetation surfaces that are intensively managed and directly influenced by the artificial cover. Land cover composition as detailed as construction material abundance (Herold et al. 2003; Roessner et al. 2001), vegetation characteristics such as type, structure or condition (Alonzo et al. 2015; Degerickx et al. 2018; Delegido et al. 2014; Pontius et al. 2017), information on vertical structures and surface roughness (Zhou et al. 2005), water run-off potentials (Weng 2001) or spatial-temporal surface temperature changes (Deng and Wu 2013; Imhoff et al. 2010) can be deduced when the full spectrum of remote sensing technology is considered, including multi- and hyperspectral optical sensors, thermal sensors, microwave and lidar systems (Small et al. 2018). This way, ecologically relevant information such as spatial patterns of impervious and vegetated surface, biomass estimates and inputs for microclimatic or hydrological models can be derived (Carlson and Arthur 2000; Heldens et al. 2017; Huang et al. 2013; Ngie et al. 2014; Voogt and Oke 2003).

The contribution from optical sensors to the list of variables that can be derived from remote sensing data is mostly related to the identification of land cover types and materials or the type and biophysical condition of urban vegetation. Particularly, the spectral information from imaging spectroscopy data adds relevant detail to the analysis of the urban environment, for example, to the derivation of ecological indicators (Behling et al. 2015) or urban structure types (Heiden et al. 2012), the characterization of urban greenness (Degerickx et al. 2018; Delegido et al. 2014) or modeling meteorological variables (Brackx et al. 2017). Nevertheless, imaging spectroscopy and optical remote sensing in general also face challenges when urban environments are mapped. On the one hand, mapping is complicated by the high number of spectrally mixed pixels typical of urban imagery with a great variety of surface materials and high frequent spatial change (Small 2003). Phenomena such as shadow, illumination differences and object displacement from vertical 
structures, on the other hand, hamper the remote sensing analyses at all scales (Adeline et al. 2013; van der Linden and Hostert 2009). The spectral ambiguity between land cover types, due to the presence of construction materials with similar reflectance properties, and the spectral heterogeneity within single land covers, due to the high diversity of materials and species or the high spectral variability of the single materials or species, constitute further challenges (Fig. 1; Herold and Roberts 2005; Herold et al. 2004; Small 2001; van der Linden et al. 2007). Here, imaging spectroscopy data have proven more reliable than data from multispectral instruments. Urban vegetation also marks an especially challenging case. Street trees, for example, live under extreme conditions, often being exposed to higher actinic stress, lower water supplies and higher loads of air pollution (Damm 2008). Their sparse spatial distribution requires very high spatial resolution imagery for accurate mapping (Tigges et al. 2013), while urban street canyons may cause extreme illumination situations and trees are often obscured by surrounding buildings (van der Linden and Hostert 2009). Again, an increased spectral information adds to the quality of results (Alonzo et al. 2014). The combined complexity of material composition and vertical structures also renders the modeling of radiative transfer challenging and processing intensive. Despite the existence of ray-tracing models that can model urban radiative transfer under certain conditions (Gastellu-Etchegorry et al. 2015), studies reporting the use of model inversion for mapping biophysical parameters for different land covers at relevant spatial extent are still missing.

Given the fine-scale spatial patterns and highly frequent spectral variation of urban surfaces, the spatial resolution of remote sensing imagery becomes a key factor in mapping urban environments. Thus, the soon-to-come step from airborne to spaceborne imaging spectroscopy marks a major challenge for urban remote sensing. This overview paper reflects on the state of imaging spectroscopy and the respective potentials and challenges
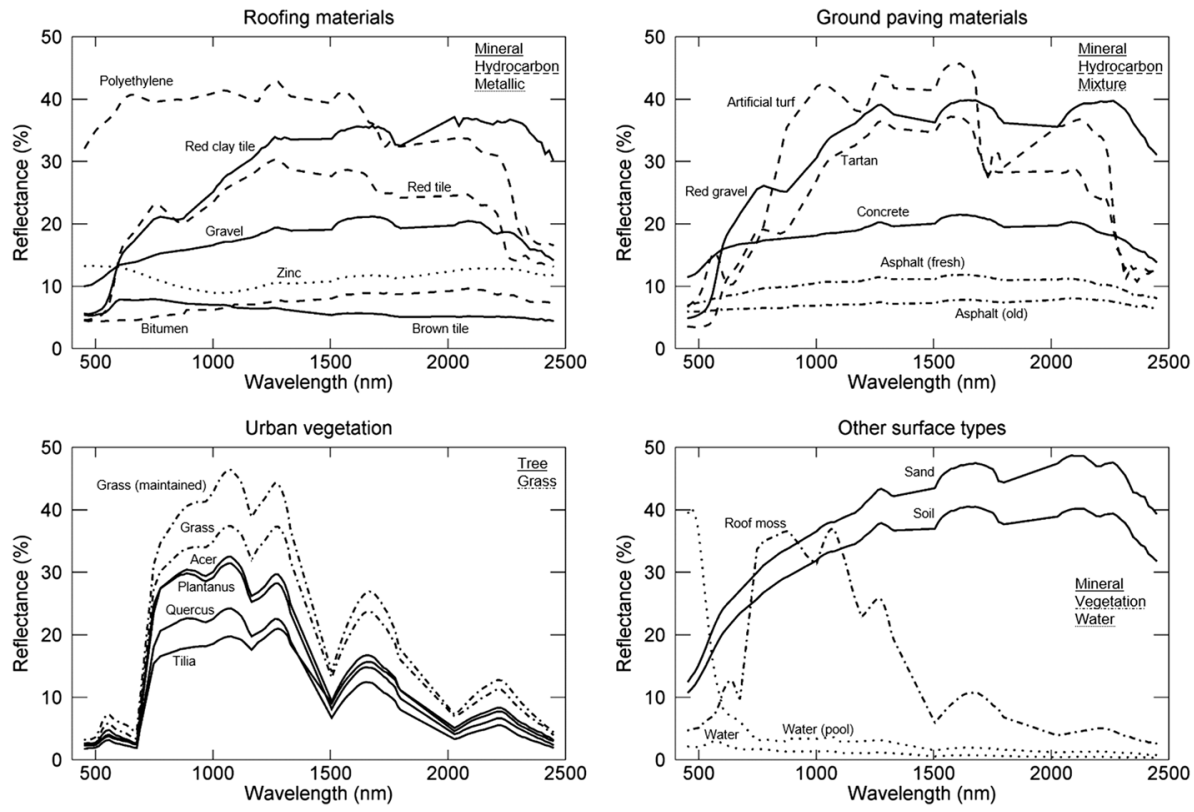

Fig. 1 Examples for urban surface spectra ordered by land cover type. Plots reveal the spectral heterogeneity within built-up land cover classes and the similarity between them 
in the context of future spaceborne imaging spectrometers such as the Environmental Mapping and Analysis Program EnMAP (Guanter et al. 2015) or the Hyperspectral Infrared Imager HyspIRI (Hochberg et al. 2015).

\section{State-of-the-Art in Imaging Spectroscopy of Urban Environments}

Imaging spectroscopy has been shown to be a powerful tool for remote sensing of urban environments in many studies (Herold et al. 2007; Roberts et al. 2012). Its high spectral information content overcomes the challenges caused by spectral ambiguities in multispectral data to a certain extent (Herold et al. 2004) and allows analysis at different levels of thematic detail (Fig. 2). Airborne imaging spectroscopy data have long been used for detailed urban mapping up to the material level (e.g., Heiden et al. 2007; Herold et al. 2003). However, airborne observations are mostly constrained in spatial coverage (i.e., usually only parts of cities) and temporal frequency (i.e., irregular and usually not multiple annual observations), which so far has led to a limited use in city- to regional-scale urban applications such as urban ecosystem management or urban planning. Relatively few studies include satellite-based imaging spectroscopy data (e.g., Demarchi et al. 2012a; Fan and Deng 2014; Licciardi and Del Frate 2011; Weng et al. 2008) or simulations of future spaceborne systems (e.g., Okujeni et al. 2015; Roberts et al. 2012; Rosentreter et al. 2017), which lack the spatial detail needed for many applications, especially in the context of urban planning. Once upcoming spaceborne sensors provide high-quality full-range imaging spectroscopy data with large area coverage and high temporal frequency, the number of urban environmental applications with imaging spectroscopy data that do not require very high spatial detail is expected to increase, for example, the mapping of physical composition for urban climate models.

The decrease in spatial resolution, when moving from air- to spaceborne observations, leads to the aggregation of different surface types into larger pixels (Fig. 3) and, hence, to severe mixing of spectral signals (Fig. 4). The number of pure spectral signals that mark the vertices of the spectral feature space is quickly reduced when pixels from different surface types are aggregated. At $30 \mathrm{~m}$ spatial resolution, only few pure clusters remain along the edges of the typical triangular mixing space described by Small (2005), while the majority of pixels is located in the center of the spectral feature space. With increasing spectral mixing, the distinct spectral characteristics of unique urban materials are lost, which makes classification at the urban material level

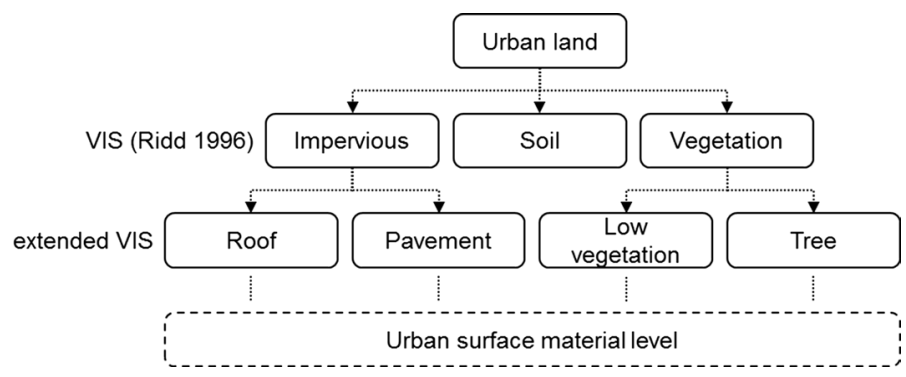

Fig. 2 Hierarchical land cover categorization scheme adopted for urban mapping. VIS refers to a vegetation-impervious surface-soil (V-I-S) model. From Heiden et al. (2007, modified) 


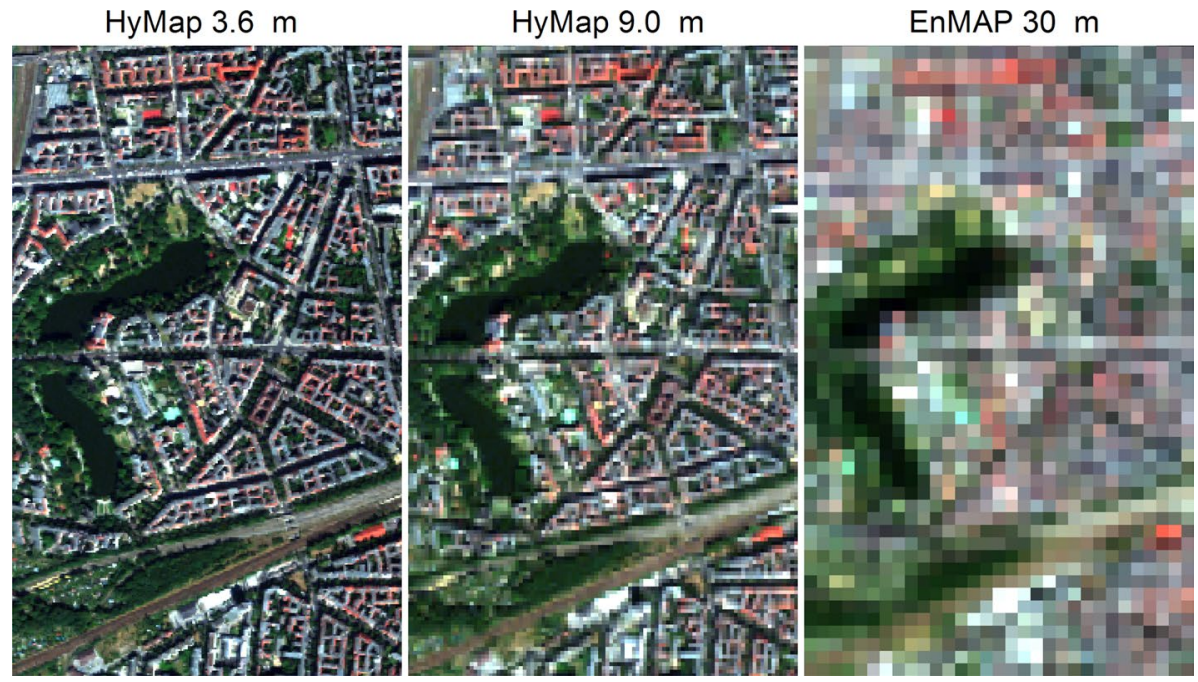

Fig. 3 True color images from airborne Hyperspectral Mapper (HyMap) data at 3.6 and $9.0 \mathrm{~m}$ and from simulated Environmental Mapping and Analysis Program (EnMAP) data at $30 \mathrm{~m}$ spatial resolution for Berlin, Germany, showing the loss of spatial and spectral detail caused by spatial aggregation of urban structures
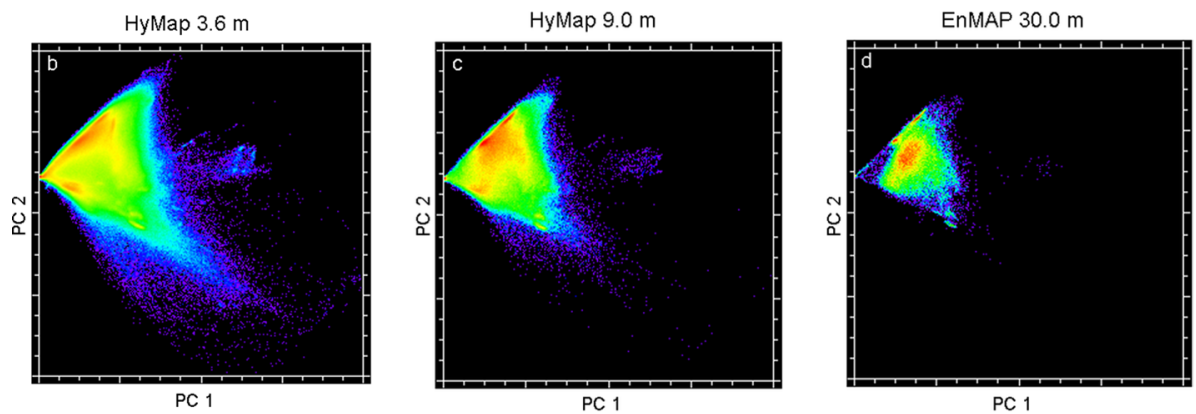

Fig. 4 Two-dimensional spectral feature space along first and second principal components of data from HyMap at 3.6 and $9 \mathrm{~m}$ spatial resolution and from simulated EnMAP data at $30 \mathrm{~m}$. Density is displayed as color range from dark blue over green and yellow to red; scaling is irrelevant, yet identical. Details see text

unrealistic. Urban mapping at coarser resolutions therefore rather focuses on delineating the three main urban cover types vegetation, impervious and soil (VIS) (Ridd 1995), or extended variants of the VIS framework (Fig. 2; e.g., Okujeni et al. 2015; Roberts et al. 2012; Weng et al. 2008). Due to the significant influence of spatial resolution on the level of thematic detail and accuracy of existing studies, the remainder of this section will be structured along the spatial scale, starting with the laboratory and field (indefinitely high spatial resolution) through to the airborne (very high to high spatial resolution) and spaceborne (medium spatial resolution) scale. For each spatial scale, presented literature is organized along the type of application, starting with qualitative analysis, that is, discrete classification into land cover, material or vegetation types, leading over 
to quantitative analysis, that is, mapping of cover type fractions, and ending with the description of biophysical parameters, if existent at that scale.

Field and laboratory spectroscopy allows for the most detailed spectral measurements of urban materials or urban vegetation, given the very high number of spectral bands, for example, 2150 in the case of the full-range Analytical Spectral Devices (ASD) spectroradiometer, indefinitely high spatial detail, and (at least partially) standardized illumination. Multiple spectral measurements from the field or laboratory are usually collected in spectral libraries and analyzed for characteristics that have been acquired in parallel to the measurement, for example, material composition or biophysical variables. However, only few results from urban areas using field- or laboratory-based spectral libraries are reported in the literature. Herold et al. (2004) developed a comprehensive field spectral library of more than 4500 individual spectra for the vicinity of Santa Barbara, USA. In a systematic statistical analysis, they revealed opportunities and limitations for separating urban land cover types and for identifying important wavelength regions for urban remote sensing. Ben-Dor et al. (2001) developed an urban spectral library from a collective spectral database (Price 1995) to explore the visible and near-infrared spectral characteristics of urban cover types typical for Tel-Aviv, Israel. In a follow-up study, the use of the entire visible to shortwave-infrared region based on a spectral library obtained from in situ measurements for the recognition of urban materials was illustrated (Ben-Dor 2001).

Pure image spectra that have been extracted from spectrally homogeneous regions in high spatial resolution airborne imaging spectroscopy data constitute an alternative means to develop or complement urban spectral libraries. For example, Heiden et al. (2007) developed a comprehensive field and image spectral library of more than 21,000 urban materials representative for many German cities. They explored this library to identify unique material-specific spectral features that are robust against spectral overlap between material classes and within-class variability. Findings obtained from field, laboratory or high spatial resolution image spectral libraries mainly contribute to an improved understanding of general spectral properties of urban materials, including their brightness (albedo), slope and shape of the broad continuum, absorption features or separability.

Beyond the description of urban materials, spectral measurements are also used to describe vegetation properties and the relevance of very high spectral detail has, for example, been shown in the context of mapping urban air pollution based on leaf chlorophyll content and fluorescence yield of urban street trees (Brackx et al. 2017; Van Wittenberghe et al. 2013). Even though the mixed pixel challenge is not tackled at this scale, insights into opportunities and limitations of imaging spectroscopy for urban mapping at airborne and spaceborne scales are provided.

With airborne imaging spectroscopy at 1-5 m spatial resolution, classification of urban land cover has been shown to be highly accurate (e.g., Demarchi et al. 2014; Roessner et al. 2001). The level of thematic detail in classification approaches (compare Fig. 2) is related to the subsequent analyses and reaches from extended variants of VIS (e.g., Roessner et al. 2001; van der Linden et al. 2007), to more material-oriented mapping approaches (Franke et al. 2009; Herold et al. 2003). Priem and Canters (2016) used airborne prism experiment (APEX) data of $2 \mathrm{~m}$ spatial resolution and 252 spectral bands for mapping the city center of Brussels, Belgium, with 27 material and land cover classes (Fig. 5). They applied kernel-based support vector machines from the field of machine learning and derived a map of $81 \%$ overall accuracy (Fig. 5c). They could reliably separate distinct types of roofs (ceramic tiles, shingle, fiber cement), pavement (asphalt, concrete, cobble stone), soil, trees and grass. The strength of machine learning approaches like support vector classification for the analysis of urban imaging 

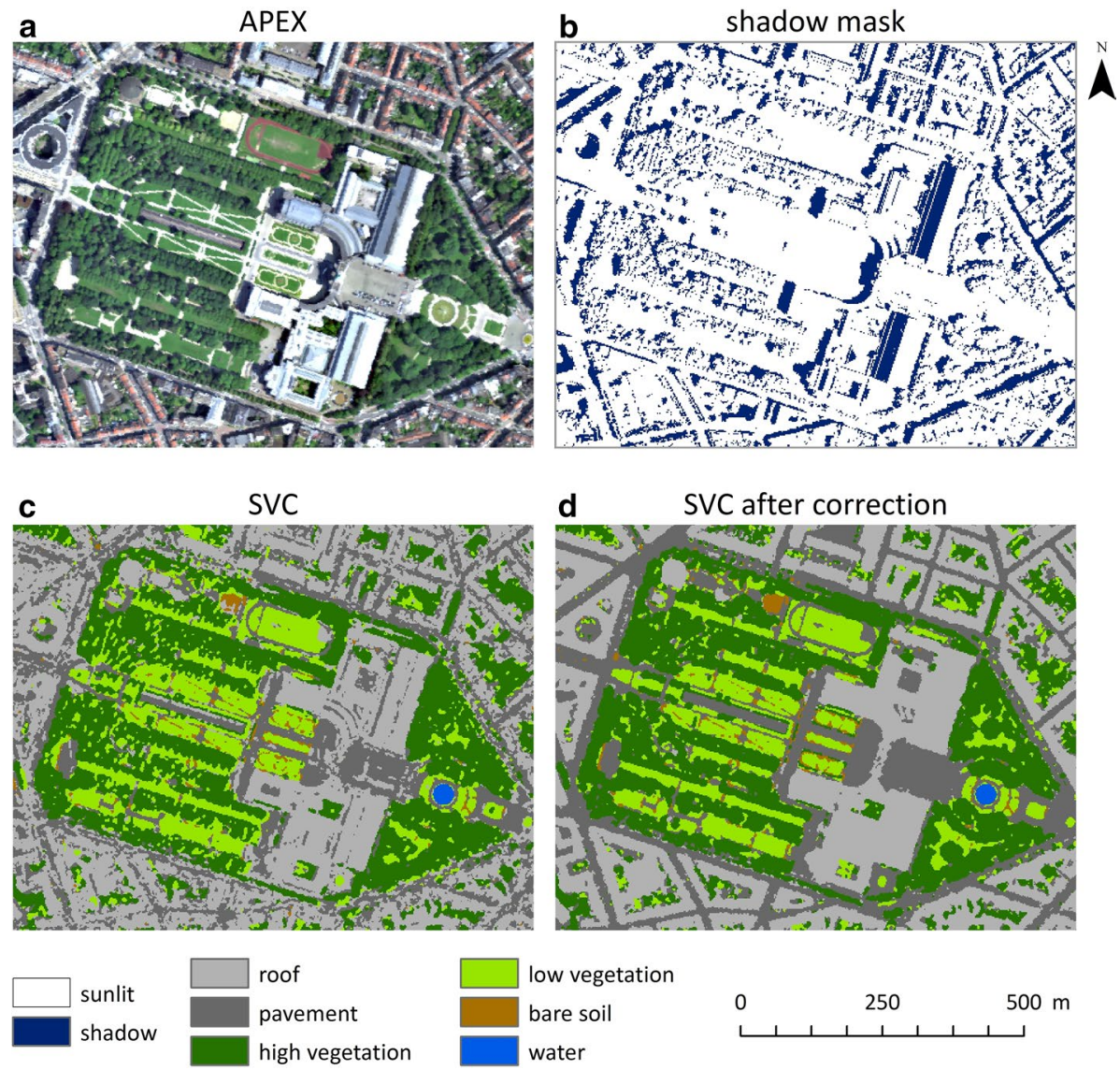

Fig. 5 True color red/green/blue (RGB) visualization of APEX data from Brussels, Belgium (a), shadow mask representing the digital surface model information used for post-classification correction (b) and the results from support vector classification (SVC) without (c) and with (d) inclusion of the digital surface model. From Priem and Canters (2016)

spectroscopy data at very high spatial resolution is also shown in studies aiming at extended VIS classes that include multimodal spectral distributions, typical for urban environments (e.g., van der Linden et al. 2007). An alternative to machine learning classification is classification based on unmixing approaches (Franke et al. 2009) or combinations of unmixing and statistical classification (Roessner et al. 2001). Despite the high level of thematic detail and accuracy that is achieved with very high spatial and spectral resolution imaging spectroscopy data and powerful classifiers, some typical urban challenges like spectral ambiguity and low signal in shadowed areas remain. Priem and Canters (2016), for example, further improved their results from 81 to $88 \%$ overall accuracy over Brussels by post-processing of their APEX-based map using information from high-resolution lidar data (Fig. 5d). Studies focusing on classifying vegetation cover types in urban areas come to similar conclusions: very high-resolution airborne visible/infrared imaging spectrometer (AVIRIS) data alone allowed high overall accuracies when mapping, for example, 15 tree species over Santa Barbara, USA, while tree crown 
mapping was more reliable when including vertical density measures from full waveform lidar data (Alonzo et al. 2013, 2014).

Even at spatial resolutions below $5 \mathrm{~m}$, a high number of spectral mixings occur and single pixels are often composed of more than one spectral endmember, that is, a spectral signal that is considered as being the pure representation of a cover type at the thematic level of the given research. Wetherley et al. (2017), for example, stated that about half of the pixels in a 4-m resolution AVIRIS Next-Generation (NG) image consisted of two or more endmembers according to model selection in a multiple endmember spectral mixture analysis (MESMA). This finding is confirmed by a multi-scale analysis at the thematic level of extended VIS that was synthesized in the context of this review from existing studies: Approximately $45 \%$ of the pixels in 3.6-m resolution data are composed of more than two of the extended VIS land cover types according to detailed reference maps (Fig. 6). The share of mixed pixels and the number of land cover types mixed in single pixels increases with coarser spatial resolution.

To effectively cope with the spectral mixing without information loss, quantitative mapping approaches, that is, approaches estimating land cover fractions within pixels, are used to estimate sub-pixel fractions of urban land cover at the pixel scale. Okujeni et al. (2013) showed that the high information content of airborne imaging spectroscopy data allowed for extended VIS fraction mapping, that is, impervious, the $I$, into roofs and paved surfaces and vegetation, the $V$, into trees and low vegetation, in a support vector regression approach that used synthetically mixed training data from a 3.6-m HyMap data image endmember spectral library. Similar results for an extended VIS framework are reported by Degerickx et al. (2017) on the same data set using MESMA with different endmember selection techniques and Wetherley et al. (2017) using AVIRIS NG data at 4 m with MESMA, as well as by Chen et al. (2017) using reflective optics system imaging spectrometer (ROSIS) data at $1.3 \mathrm{~m}$ covering the visible to near-infrared range and a more recent sparse spectral unmixing approach.

Beyond mapping and quantifying of urban land cover, the information in high spatial and spectral resolution airborne data can be used to characterize the state and condition of urban green. Degerickx et al. (2018) employ 2-m resolution APEX data in combination with airborne lidar data to retrieve the chlorophyll content and leaf area index of individual urban trees in the city of Brussels, Belgium, using partial least squares regression. By combining these outcomes into an objective urban tree health assessment, which is shown to

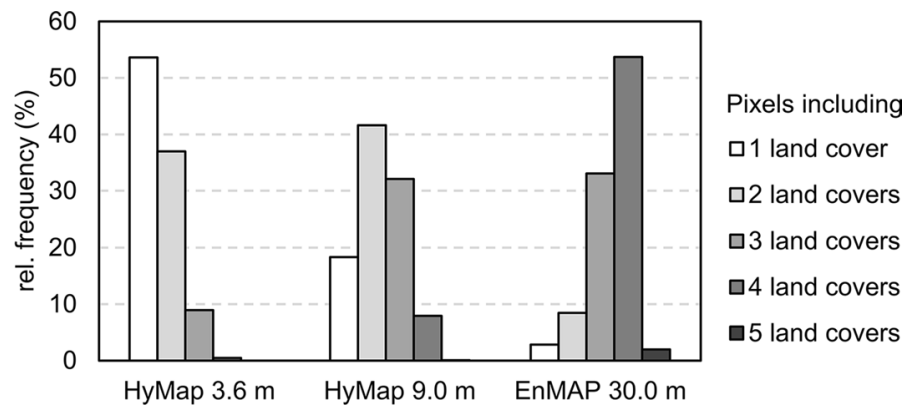

Fig. 6 Relative frequencies of pixels including different numbers of discrete land cover types in HyMap imagery at 3.6 and $9 \mathrm{~m}$ spatial resolution and a simulated EnMAP image at $30 \mathrm{~m}$ resolution. High-resolution land cover reference information included the extended VIS classes roof, pavement, low vegetation, trees and soil. Based on data from Okujeni et al. (2013, 2014, 2015) 
match the results from a traditional visual tree health assessment, the authors clearly illustrate the potential of imaging spectroscopy for urban tree health monitoring.

With airborne imagery at coarser spatial resolution of $>5 \mathrm{~m}$ ground sampling distance, classification into discrete classes has hardly been used in the urban context and quantitative mapping techniques are becoming even more important. Several authors report on the strength of imaging spectroscopy data in this context. Wetherley et al. (2017) compared results derived from AVIRIS NG at $4 \mathrm{~m}$ and from AVIRIS Classic at $18 \mathrm{~m}$ using MESMA with different image endmember library variants. The two AVIRIS sensors were flown at different altitudes and could, hence, be processed at native resolutions. For their best fraction estimates, the authors reported similar accuracies for the green vegetation, impervious and pervious (mean $R^{2}$ of 0.933 at $4 \mathrm{~m}$ and 0.900 at $18 \mathrm{~m}$ ). For spectrally more similar cover types in the extended VIS model, that is, turf grass, tree, paved, roof, nonphotosynthetic vegetation and soil, they discovered a decrease in accuracies (mean $R^{2}$ of 0.837 at $4 \mathrm{~m}$ and 0.760 at $18 \mathrm{~m}$ ). Despite this decrease, these findings indicate the possibility to work with more detailed classes when adopting coarser resolution data. Okujeni et al. (2014) transferred their findings from $3.6 \mathrm{~m}$ data to $9 \mathrm{~m}$ and reported high accuracies for the work with synthetic training data when combined with support vector regression, but also other machine learning approaches. More detailed maps on urban vegetation also require quantitative mapping frameworks. Gu et al. (2015), for example, used non-metric multidimensional scaling ordination (NMDS) to map canopy traits in 11.8-m AVIRIS data. Based on these trait maps, they predicted dominant species composition of urban forest patches. However, studies at spatial scales $>5 \mathrm{~m}$ do not achieve the accuracies of studies with higher spatial resolution (Delegido et al. 2014) or studies including structural information from, for example, lidar sensors (Alonzo et al. 2015).

Nowadays, spaceborne imaging spectrometers can acquire data at minimal ground sampling distances of $30 \mathrm{~m}$, as will be the case for EnMAP or HyspIRI (Guanter et al. 2015). So far, only few studies in urban environments have used Hyperion imagery, which comes closest to the characteristics of future systems but lacks sufficient radiometric quality in the shortwave-infrared (Kruse et al. 2003). All these studies aim for land cover fractions instead of discrete classification. Weng et al. (2008) extracted the fraction of impervious surface from Hyperion data with an RMSE of about 17\% using a VIS approach that separated high and low albedo impervious surfaces as suggested by Wu and Murray (2003) based on multispectral data. Fan and Deng (2014) achieved similar accuracies for impervious surface fractions, while separating tree and non-woody vegetation in an enhanced MESMA approach. The spaceborne compact high-resolution imaging spectrometer (CHRIS) only covers the wavelength range from 410 to $1050 \mathrm{~nm}$ and can therefore achieve 18 -m ground instantaneous field of view. It is capable of tilting to derive quasi-simultaneous image acquisitions at multiple viewing angles and has been used by various authors in an urban context (e.g., Demarchi et al. 2012a; Duca and Del Frate 2008; Licciardi and Del Frate 2011). For example, Duca and Del Frate (2008) used multi-angular acquisitions from the CHRIS instrument and improved classification accuracies of an extended VIS scheme (dark asphalt, bright asphalt, buildings, among other cover types) by almost $7 \%$ compared to a single nadir acquisition. Demarchi et al. (2012b) also showed an improvement in the accuracy of quantitative mapping of imperviousness from CHRIS data when using multiangle instead of single, close-to-nadir imagery.

The limitations of existing spaceborne imaging spectrometers have led to an increased use of data from end-to-end sensor simulations in the context of mission preparations for EnMAP or HyspIRI (Roberts et al. 2012; Segl et al. 2012). During end-to-end simulation, an at-sensor raw digital number (DN) image is modeled for an area with known reflectance 
factors, assuming realistic solar illumination and atmospheric conditions. The reflectance factors may stem from high spectral and spatial airborne imagery or from forward modeling of, for example, vegetation canopies. The full radiative path from Sun to the geographic location of the area and to the sensor is simulated, followed by a simulation of the signal's modulations within the sensor and during recording. The resulting raw DN product is afterward preprocessed to level 2a using the standard ground segment workflow. Several authors have worked on urban environments with future Earth observation imaging spectroscopy data from such simulations. Okujeni et al. (2015) used simulated EnMAP data for mapping extended VIS components. The study proved both the capability of imaging spectrometry data to quantify spectrally similar cover types like roofs and pavements, or low and high vegetation at $30 \mathrm{~m}$ and the superiority of the higher spectral resolution in comparison to multispectral Landsat data. This is in line with results from Roberts et al. (2012) using simulated HyspIRI data with MESMA and from Rosentreter et al. (2017) who used simulated EnMAP data and a multi-class SVR. They all conclude that mapping class fractions at the thematic detail of extended VIS from spaceborne imaging spectroscopy is worthwhile.

\section{User and Observational Requirements}

The literature overview in the previous section clearly shows that imaging spectroscopy data is mainly used for the identification of materials and the estimation of their associated land cover. Based on the reported state-of-the-art, the following user and observational requirements can be derived.

The requirements in terms of temporal resolution strongly depend on the thematic classes to be studied. On the one hand, individual images are usually sufficient to map anthropogenic surfaces. Ideally, the acquisition date and time minimize the share of shadow and the degree of reflectance anisotropies. The combination of leaf-on and leafoff data from the same year, on the other hand, can help quantifying deciduous tree cover or surface cover underneath canopies. The advantage of multiple images per year is even higher when mapping tree species: information from various dates to better describe phenology stages will increase separability and improve characterization of vegetation structure and vigor (e.g., using multispectral data refer to Pontius et al. 2017; Tigges et al. 2013; Wirion et al. 2017). Denser time series of acquisitions may help characterize phenology and the influences of, for example, neighboring artificial surfaces on microclimate models.

Radiometric resolution requirements are not as high as, for example, in aquatic applications (see Giardino et al. 2018, this issue). However, the analysis of images with a high amount of shadow may benefit from high radiometric resolution and better signal-to-noise ratios in order to better differentiate land cover in shaded areas (van der Linden and Hostert 2009).

Looking at spectral resolution requirements, the benefits of the high spectral information content have been demonstrated in many studies. Particularly, when classification schemes aim for a high level of detail, such as material composition, additional spectral information leads to significantly higher accuracies at all spatial scales (Herold et al. 2003, Okujeni et al. 2015). The description of vegetation characteristics in urban environments also benefits from high spectral resolution (Alonzo et al. 2014; Delegido et al. 2014; Launeau et al. 2017). 
To acquire data with very high spectral resolution from space, however, the spatial resolution must be decreased. Maps on urban material composition at more thematic detail than extended VIS schemes appear unrealistic with the near future spaceborne imaging spectrometers at $30 \mathrm{~m}$ spatial resolution, due to the high degree of spectral mixing (Fig. 4), while the level of detail as in extended VIS schemes appears feasible to differentiate (Okujeni et al. 2015; Roberts et al. 2012). To summarize the influence of spatial scale as reported in Sect. 2, results from existing studies have been collected and reanalyzed in the context of the present review (data from Okujeni et al. 2013, 2014, 2015). The deficiencies and potential of mapping extended VIS components at scales reaching from 3.6-m spatial resolution airborne data to (simulated) spaceborne resolution are illustrated in Figs. 7 and 8. Despite the significant increase in spectral mixing and loss in spatial detail, Fig. 7 shows general spatial patterns of the extended VIS fraction estimates as derived by support vector regression models that were trained with synthetic library mixtures are well preserved across scales (Fig. 7). Roof, low vegetation, trees and soil fractions can be estimated with a slight decrease in model performance when progressing from $<5$ to $30 \mathrm{~m}$ spatial resolution (Fig. 8). Pavement fractions are inaccurate and underestimated at all scales, while roofs and soils are often overestimated at very low fractions. This observation points to the general limitation of separating paved areas from roofs and soils in optical remote sensing data even when using imaging spectroscopy for urban mapping. Similarly, low vegetation is underestimated, while trees are slightly overestimated across the entire range of values. Both effects relate to spectral ambiguity of materials, high shadow fractions and high frequencies of spectral mixing along small objects or linear features.

Therefore, there is evidence that data from future spaceborne spectrometers will contribute relevant information to studies at 30-m scale and for subsequent analyses, for example, environmental models, at such spatial scales, despite the loss of spatial detail compared to airborne sensors. The final accuracy and level of detail that can be achieved with actual
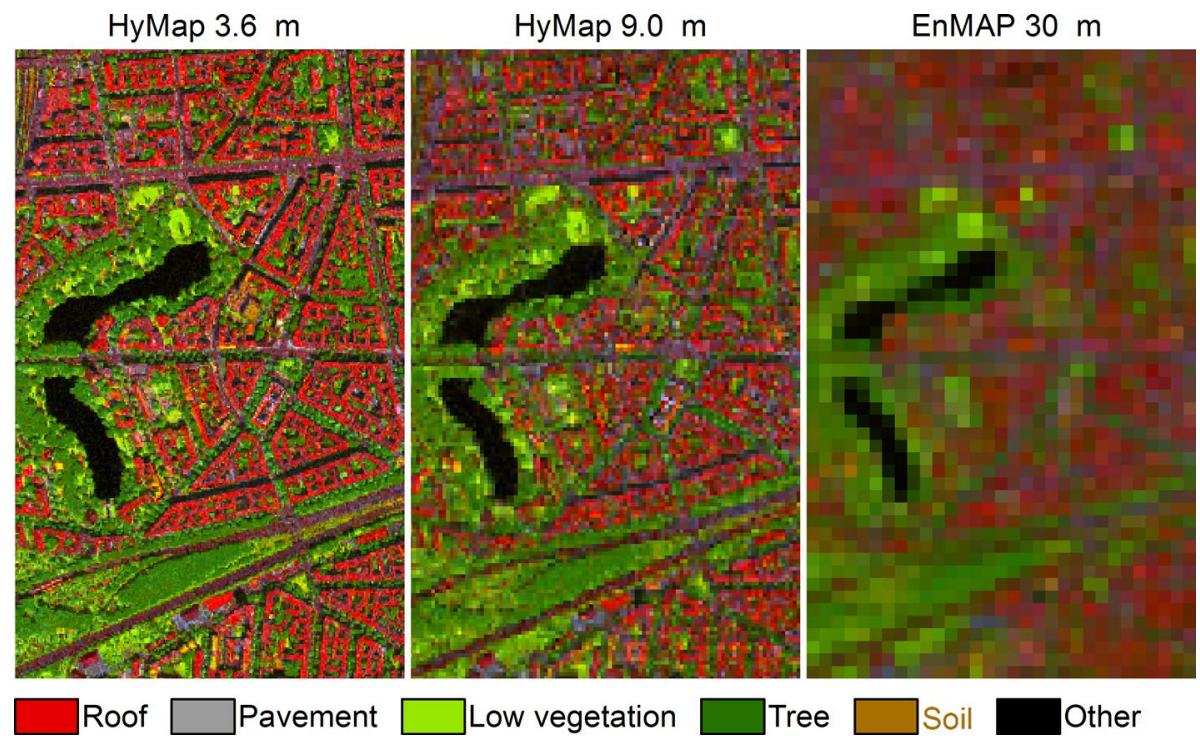

Fig.7 Quantitative land cover maps of Berlin using imaging spectroscopy data at different spatial resolutions based on the synthetic unmixing approach by Okujeni et al. (2013). Map colors are weighted averages of class colors. Gray to brown colors, as visible in the 30-m resolution map, depict multi-class mixtures 

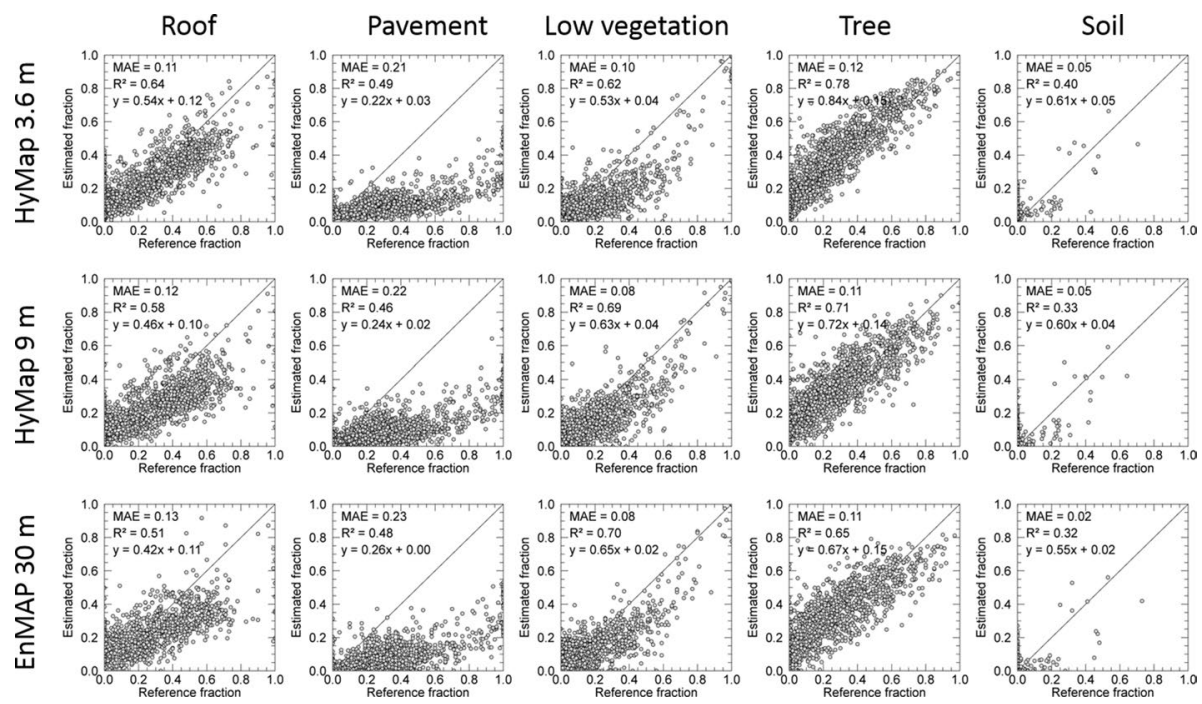

Fig. 8 Scatter plots and error metrics of fraction estimates for rooftops, paved surfaces, trees, low vegetation and soil based on imaging spectroscopy data at 3.6, 9 and $30 \mathrm{~m}$ spatial resolution. Estimates are compared to reference fractions based on very high-resolution vector layers aggregated to the 30-m raster cells of the simulated EnMAP data. Results based on reanalyzed data from Okujeni et al. $(2013,2014,2017)$

data cannot be predicted based on simulated data from end-to-end simulation. The reflectance surfaces underlying such simulations always include artefacts following the complex surface geometry of the urban environment, for example, through object displacement (van der Linden and Hostert 2009), or illumination anisotropies from large view angles in the original airborne data (Schiefer et al. 2006).

In comparison with other environments, the requirements for mapping and monitoring urban areas with Earth observation data may to some extent be similar to those from geological applications (e.g., van der Meer et al. 2012), where material identification and fraction estimates prevail. Only relatively large and homogeneous urban vegetation surfaces, for example, larger forest patches, may require similar approaches as forest mapping outside urban areas (see Hill et al., under review, this issue).

\section{Challenges and Future Directions}

Nowadays, spaceborne multispectral imagery is available from finer than $1 \mathrm{~m}$ spatial resolution for the analysis of urban environments. In the near future, imaging spectroscopy data will be acquired at $30 \mathrm{~m}$ resolution with sensors such as EnMAP and HyspIRI, as well as the Hyperspectral Imager Suite (Matsunaga et al. 2017) and PRISMA (Guarini et al. 2017). These sensors enable repeated observations almost everywhere on the globe under more standardized acquisition conditions and with operational preprocessing. Still, the selection of data sets by users working in urban environments will always depend on the intended level of spatial detail. Given the technical trade-off in spectral and spatial resolution, spaceborne imaging spectroscopy data alone will hence not automatically become number one choice, for example, by urban planners, due to the small size of most urban objects. 
To incorporate the potential of higher spectral resolution, data fusion techniques can be expected to play a pivotal role in fostering the use of such data. For the fusion with secondary optical data, approaches based on Sentinel-2 Multispectral Imager (MSI) data appear promising (Yokoya et al. 2016). The relevance of increased spatial detail in combination with high spectral information content for urban mapping has already been shown using CHRIS data (Demarchi et al. 2012b).

The benefits of including structural information especially from lidar are mentioned in Sect. 2. With the Carnegie Airborne Observatory-2 (Asner et al. 2012), similar multisensor constellations have been successfully implemented for airborne observation. Such structural information may be used at the original $30 \mathrm{~m}$ or even higher resolutions by downscaling the spectral signal as done by Alonzo et al. (2014) for analyzing single urban trees. With detailed digital surface models being available for many urban areas around the world as well as products from microwave sensors such as TanDEM-X, more fusion approaches become feasible, once imaging spectroscopy is available at higher frequencies. Attempts to achieve this in urban environments with multispectral data exist (Zhu et al. 2012).

For studies aiming at monitoring temporal developments or mapping entire regions as well as for comparative studies on urban areas at continental or even global scale, future spaceborne imaging spectrometers will introduce major advantages with regard to data availability: (1) at least for selected regions, multiple observations per month become possible and (2) data will be globally available under stable sensor characteristics and with standardized preprocessing workflows. These changes offer several opportunities for the work with imaging spectroscopy data. Yet the suite of analysis approaches will have to be adapted at some points, before being able to make ideal use of the new wealth of data. With regard to multi-temporal data sets, for example, time-series analysis has to move beyond the analysis of simple, mostly vegetation-related indices that may also be calculated from multispectral data. Such indices are better derived from instruments such as Sentinel-2 with significantly higher repetition rate and spatial detail. Instead, new spectral indices or feature extractions from waveband regions only present in imaging spectroscopy data are required (Leitão et al. 2015). This way, temporal changes may be incorporated in the analysis of urban areas to observe urban growth, densification or changes in composition.

When the same sensor and preprocessing are used for comparative analysis, the transfer of models, spectral libraries and even expert knowledge, for example, on characteristic spectral features as described in Heiden et al. (2007) will offer new ways for developing biophysically based semiempirical or purely empirical mapping models.

This will, however, require joint activities, for example, the generation of urban spectral libraries including image spectra from cities in all regions that shall be monitored. First attempts in this direction are already being made for foliar traits (e.g., Singh et al. 2015) and may in similar ways be extended for urban areas. The idea of using synthetic mixtures between different surface spectra from spectral libraries (Okujeni et al. 2017) to map surface fractions in imagery of different spectral resolution has been proven useful (Priem et al. 2016, 2017). Similarly, Wetherley et al. (2017) used spectra from images at different spatial resolutions and this way improved results at all scales. In addition, more work is needed to adapt spectral libraries to new image data sets, by pruning techniques (Degerickx et al. 2017) or extension of libraries by automated integration of unknown surface material spectra (Jilge et al. 2017).

Finally, the production of more detailed and accurate maps requires new frameworks that allow several application fields to make use of the same high-quality maps derived from urban imaging spectroscopy data. In the context of land cover mapping, advances 
were made regarding land cover classification scheme standardization. Most of urban planning activities are based on urban spatial units such as land parcels, urban blocks, urban structure types, urban biotopes or administrative units. However, the nomenclature of such units is highly complex and lack standardization and consistency. This led, for example, to the concept of Functional Urban Areas in the Urban Atlas of the European Copernicus Services (http://land.copernicus.eu/local/urban-atlas). Environmental modelers need more physical-based parameters such as abundance of impervious areas, the building density and the abundance, structure and condition of vegetation. Over the past years, the concept of local climate zone mapping, for example, has become widely recognized even beyond pure climate science. It characterizes regions of uniform surface cover, structure, material and human activity (Bechtel et al. 2015; Stewart and Oke 2012). Based on spaceborne urban surface material mapping, any urban spatial unit can be characterized and thus can support the standardized physical description of cities.

The future availability of spaceborne imaging spectroscopy data will offer room for new analysis approaches of urban environments, yet efforts at several ends are needed for an operational use of the new data.

Acknowledgements The authors are grateful to the editors of the special issue and the organizers of the ISSI workshop on Exploring the Earth's Ecosystems at a Global Scale with Imaging Spectroscopy Data in Bern, Switzerland, in November 2016, where the present paper was framed. The work of the authors was supported by the German Federal Ministry of Economic Affairs and Energy in the framework of the EnMAP Core Science Team (FKZ 50EE1622) and by the Belgian Science Policy Office in the framework of the Stereo III Project UrbanEARS (SR/00/307).

\section{References}

Adeline KRM, Chen M, Briottet X, Pang SK, Paparoditis N (2013) Shadow detection in very high spatial resolution aerial images: a comparative study. ISPRS J Photogramm Remote Sens 80:21-38. https:// doi.org/10.1016/j.isprsjprs.2013.02.003

Alberti M (2005) The effects of urban patterns on ecosystem function. Int Reg Sci Rev 28:168-192

Alonzo M, Roth K, Roberts D (2013) Identifying Santa Barbara's urban tree species from AVIRIS imagery using canonical discriminant analysis. Remote Sens Lett 4:513-521. https://doi.org/10.1080/21507 04X.2013.764027

Alonzo M, Bookhagen B, Roberts DA (2014) Urban tree species mapping using hyperspectral and lidar data fusion. Remote Sens Environ 148:70-83. https://doi.org/10.1016/j.rse.2014.03.018

Alonzo M, Bookhagen B, McFadden JP, Sun A, Roberts DA (2015) Mapping urban forest leaf area index with airborne lidar using penetration metrics and allometry. Remote Sens Environ 162:141-153. https ://doi.org/10.1016/j.rse.2015.02.025

Asner GP et al (2012) Carnegie Airborne Observatory-2: Increasing science data dimensionality via high-fidelity multi-sensor fusion. Remote Sens Environ 124:454-465. https://doi.org/10.1016/j. rse.2012.06.012

Bechtel B et al (2015) Mapping local climate zones for a worldwide database of the form and function of cities. ISPRS Int J Geoinf 4:199. https://doi.org/10.3390/ijgi4010199

Behling R, Bochow M, Foerster S, Roessner S, Kaufmann H (2015) Automated GIS-based derivation of urban ecological indicators using hyperspectral remote sensing and height information. Ecol Ind 48:218-234. https://doi.org/10.1016/j.ecolind.2014.08.003

Ben-Dor E (2001) Imaging spectrometry for urban applications. In: van der Meer FD, De Jong SM (eds) Imaging spectrometry-basic principles and prospective applications. Remote sensing and digital image processing, vol 4. Springer, Dordrecht, pp 243-281

Ben-Dor E, Levin N, Saaroni H (2001) A spectral based recognition of the urban environment using the visible and near-infrared spectral region $(0.4-1.1 \mu \mathrm{m})$. A case study over Tel-Aviv, Israel. Int J Remote Sens 22:2193-2218 
Brackx M, Van Wittenberghe S, Verhelst J, Scheunders P, Samson R (2017) Hyperspectral leaf reflectance of Carpinus betulus L. saplings for urban air quality estimation. Environ Pollut 220:159-167. https:// doi.org/10.1016/j.envpol.2016.09.035

Carlson TN, Arthur ST (2000) The impact of land use-land cover changes due to urbanization on surface microclimate and hydrology: a satellite perspective. Glob Planet Change 25:49-65

Chen F, Wang K, Van de Voorde T, Tang TF (2017) Mapping urban land cover from high spatial resolution hyperspectral data: an approach based on simultaneously unmixing similar pixels with jointly sparse spectral mixture analysis. Remote Sens Environ 196:324-342. https://doi.org/10.1016/j. rse.2017.05.014

Damm A (2008) Hyperspektrale Fernerkundung zur Ableitung pflanzenphysiologischer Parameter von Stadtbäumen - Strahlungstransfermodellierung für Berliner Kastanienbestände. Dissertation, Humboldt-Universität zu Berlin

Degerickx J, Okujeni A, Iordache M-D, Hermy M, van der Linden S, Somers B (2017) A novel spectral library pruning technique for spectral unmixing of urban land cover. Remote Sens 9:565

Degerickx J, Roberts D, McFadden JP, Hermy M, Somers B (2018) Urban tree health assessment using airborne hyperspectral and LiDAR imagery. Int J Appl Earth Obs Geoinf 73:26-38

Delegido J et al (2014) Chlorophyll content mapping of urban vegetation in the city of Valencia based on the hyperspectral NAOC index. Ecol Ind 40:34-42. https://doi.org/10.1016/j.ecolind.2014.01.002

Demarchi L, Canters F, Chan JC-W, van de Voorde T (2012a) Multiple endmember unmixing of CHRIS/ Proba imagery for mapping impervious surfaces in urban and suburban environments. IEEE Trans Geosci Remote Sens 50:3409-3424. https://doi.org/10.1109/tgrs.2011.2181853

Demarchi L, Chan JC-W, Ma J, Canters F (2012b) Mapping impervious surfaces from superresolution enhanced CHRIS/Proba imagery using multiple endmember unmixing. ISPRS J Photogramm Remote Sens 72:99-112. https://doi.org/10.1016/j.isprsjprs.2012.05.015

Demarchi L, Canters F, Cariou C, Licciardi G, Chan JC-W (2014) Assessing the performance of two unsupervised dimensionality reduction techniques on hyperspectral APEX data for high resolution urban land-cover mapping. ISPRS J Photogramm Remote Sens 87:166-179. https://doi.org/10.1016/j.isprs jprs.2013.10.012

Deng C, Wu C (2013) Examining the impacts of urban biophysical compositions on surface urban heat island: a spectral unmixing and thermal mixing approach. Remote Sens Environ 131:262-274. https:// doi.org/10.1016/j.rse.2012.12.020

Duca R, Del Frate F (2008) Hyperspectral and multiangle CHRIS-PROBA images for the generation of land cover maps. IEEE Trans Geosci Remote Sens 46:2857-2866. https://doi.org/10.1109/tgrs.2008.20007 41

Fan F, Deng Y (2014) Enhancing endmember selection in multiple endmember spectral mixture analysis (MESMA) for urban impervious surface area mapping using spectral angle and spectral distance parameters. Int J Appl Earth Obs Geoinf 33:290-301. https://doi.org/10.1016/j.jag.2014.06.011

Fenger J (1999) Urban air quality. Atmos Environ 33:4877-4900

Franke J, Roberts DA, Halligan K, Menz G (2009) Hierarchical multiple endmember spectral mixture analysis (MESMA) of hyperspectral imagery for urban environments. Remote Sens Environ 113:1712-1723

Gastellu-Etchegorry J-P et al (2015) Discrete anisotropic radiative transfer (DART 5) for modeling airborne and satellite spectroradiometer and LIDAR acquisitions of natural and urban landscapes. Remote Sens $7: 1667$

Giardino C et al (2018) Imaging spectrometry of inland and coastal waters: state of the art, achievements and perspectives. Surv Geophy. https://doi.org/10.1007/s10712-018-9476-0

Grimm NB, Faeth SH, Golubiewski NE, Redman CL, Wu JG, Bai XM, Briggs JM (2008) Global change and the ecology of cities. Science 319:756-760. https://doi.org/10.1126/science.1150195

Grimmond S (2007) Urbanization and global environmental change: local effects of urban warming. Geogr J 173:83-88. https://doi.org/10.1111/j.1475-4959.2007.232_3.x

Gu H, Singh A, Townsend PA (2015) Detection of gradients of forest composition in an urban area using imaging spectroscopy. Remote Sens Environ 167:168-180. https://doi.org/10.1016/j.rse.2015.06.010

Guanter L et al (2015) The EnMAP spaceborne imaging spectroscopy mission for Earth observation. Remote Sens 7:8830

Guarini R, Loizzo R, Longo F, Mari S, Scopa T, Varacalli G (2017) Overview of the Prisma space and ground segment and its hyperspectral products. Paper presented at the proceedings of 2017 ieee international geoscience and remote sensing symposium, July 23-28, 2017, Fort Worth, Texas

Harlan SL, Brazel AJ, Prashad L, Stefanov WL, Larsen L (2006) Neighborhood microclimates and vulnerability to heat stress. Soc Sci Med 63:2847-2863. https://doi.org/10.1016/j.socscimed.2006.07.030

Hatt BE, Fletcher TD, Walsh CJ, Taylor SL (2004) The influence of urban density and drainage infrastructure on the concentrations and loads of pollutants in small streams. Environ Manag 34:112-124 
Heiden U, Segl K, Roessner S, Kaufmann H (2007) Determination of robust spectral features for identification of urban surface materials in hyperspectral remote sensing data. Remote Sens Environ 111:537-552

Heiden U, Heldens W, Roessner S, Segl K, Esch T, Mueller A (2012) Urban structure type characterization using hyperspectral remote sensing and height information. Landsc Urban Plan 105:361-375. https://doi.org/10.1016/j.landurbplan.2012.01.001

Heldens W, Heiden U, Esch T, Mueller A, Dech S (2017) Integration of remote sensing based surface information into a three-dimensional microclimate model. ISPRS J Photogramm Remote Sens 125:106-124. https://doi.org/10.1016/j.isprsjprs.2017.01.009

Herold M, Roberts D (2005) Spectral characteristics of asphalt road aging and deterioration: implications for remote-sensing applications. Appl Opt 44:4327-4334

Herold M, Gardner ME, Roberts DA (2003) Spectral resolution requirements for mapping urban areas. IEEE Trans Geosci Remote Sens 41:1907-1919

Herold M, Roberts DA, Gardner ME, Dennison PE (2004) Spectrometry for urban area remote sensing-development and analysis of a spectral library from 350 to $2400 \mathrm{~nm}$. Remote Sens Environ 91:304-319

Herold M, Schiefer S, Hostert P, Roberts DA (2007) Applying imaging spectrometry in urban areas. In: Quattrochi DA, Weng QH (eds) Urban remote sensing. CRC Press Inc., Boca Raton, pp 137-161

Hill J, Buddenbaum H, Townsend PA Imaging spectroscopy of forest ecosystems. Surv Geophys (under review)

Hochberg EJ, Roberts DA, Dennison PE, Hulley GC (2015) Special issue on the hyperspectral infrared imager (HyspIRI): emerging science in terrestrial and aquatic ecology, radiation balance and hazards. Remote Sens Environ 167:1-5. https://doi.org/10.1016/j.rse.2015.06.011

Huang Y, Yu B, Zhou J, Hu C, Tan W, Hu Z, Wu J (2013) Toward automatic estimation of urban green volume using airborne LiDAR data and high resolution remote sensing images. Front Earth Sci 7:43-54. https://doi.org/10.1007/s11707-012-0339-6

Imhoff ML, Zhang P, Wolfe RE, Bounoua L (2010) Remote sensing of the urban heat island effect across biomes in the continental USA. Remote Sens Environ 114:504-513. https://doi.org/10.1016/j. rse.2009.10.008

Jilge M, Heiden U, Habermeyer M, Mende A, Juergens C (2017) Detecting unknown artificial urban surface materials based on spectral dissimilarity analysis. Sensors 17:1826

Kennedy C et al (2009) Greenhouse gas emissions from global cities. Environ Sci Technol 43:72977302. https://doi.org/10.1021/es900213p

Kruse FA, Boardman JW, Huntington JF (2003) Comparison of airborne hyperspectral data and EO-1 Hyperion for mineral mapping. IEEE Trans Geosci Remote Sens 41:1388-1400. https://doi. org/10.1109/tgrs.2003.812908

Lambin EF et al (2001) The causes of land-use and land-cover change: moving beyond the myths. Glob Environ Change 11:261-269. https://doi.org/10.1016/S0959-3780(01)00007-3

Launeau P et al (2017) Airborne hyperspectral mapping of trees in an urban area. Int J Remote Sens 38:1277-1311. https://doi.org/10.1080/01431161.2017.1285080

Lawler JJ et al (2014) Projected land-use change impacts on ecosystem services in the United States. Proc Natl Acad Sci 111:7492-7497. https://doi.org/10.1073/pnas.1405557111

Leitão P, Schwieder M, Suess S, Okujeni A, Galvão L, van der Linden S, Hostert P (2015) Monitoring natural ecosystem and ecological gradients: perspectives with EnMAP. Remote Sens 7:13098

Licciardi GA, Del Frate F (2011) Pixel unmixing in hyperspectral data by means of neural networks. IEEE Trans Geosci Remote Sens 49:4163-4172. https://doi.org/10.1109/tgrs.2011.2160950

Matsunaga T et al (2017) Current status of hyperspectral imager suite (HISUI) onboard International Space Station (ISS). Paper presented at the proceedings of 2017 IEEE international geoscience and remote sensing symposium, July 23-28, 2017, Fort Worth, Texas

Ngie A, Abutaleb K, Ahmed F, Darwish A, Ahmed M (2014) Assessment of urban heat island using satellite remotely sensed imagery: a review. S Afr Geogr J 96:198-214. https://doi.org/10.1080/03736 245.2014.924864

Oke TR (1982) The energetic basis of the urban heat island. Q J R Meteorol Soc 108:1-24. https://doi. org/10.1002/qj.49710845502

Okujeni A, van der Linden S, Tits L, Somers B, Hostert P (2013) Support vector regression and synthetically mixed training data for quantifying urban land cover. Remote Sens Environ 137:184-197. https://doi.org/10.1016/j.rse.2013.06.007

Okujeni A, van der Linden S, Jakimow B, Rabe A, Verrelst J, Hostert P (2014) A comparison of advanced regression algorithms for quantifying urban land cover. Remote Sens 6:6324-6346 
Okujeni A, van der Linden S, Hostert P (2015) Extending the vegetation-impervious-soil model using simulated EnMAP data and machine learning. Remote Sens Environ 158:69-80. https://doi. org/10.1016/j.rse.2014.11.009

Okujeni A, van der Linden S, Suess S, Hostert P (2017) Ensemble learning from synthetically mixed training data for quantifying urban land cover with support vector regression. IEEE J Sel Top Appl Earth Obs Remote Sens 10:1640-1650. https://doi.org/10.1109/JSTARS.2016.2634859

Pauleit S, Ennos R, Golding Y (2005) Modeling the environmental impacts of urban land use and land cover change-a study in Merseyside. UK Landsc Urban Plan 71:295-310

Pickett STA et al (2011) Urban ecological systems: scientific foundations and a decade of progress. J Environ Manag 92:331-362. https://doi.org/10.1016/j.jenvman.2010.08.022

Pontius J, Hanavan RP, Hallett RA, Cook BD, Corp LA (2017) High spatial resolution spectral unmixing for mapping ash species across a complex urban environment. Remote Sens Environ 199:360-369. https://doi.org/10.1016/j.rse.2017.07.027

Price JC (1995) Examples of high resolution visible to near-infrared reflectance spectra and a standardized collection for remote sensing studies. Int J Remote Sens 16:993-1000. https://doi. org/10.1080/01431169508954459

Priem F, Canters F (2016) Synergistic use of LiDAR and APEX hyperspectral data for high-resolution urban land cover mapping. Remote Sens 8:787

Priem F, Okujeni A, van der Linden S, Canters F (2016) Use of multispectral satellite imagery and hyperspectral endmember libraries for urban land cover mapping at the metropolitan scale. In: SPIE remote sensing. SPIE, p 100080K. https://doi.org/10.1117/12.2240929

Priem F, Canters F, Okujeni A, van der Linden S (2017) Optimizing mixed spectra generation for regression-based unmixing of land cover in urban areas. In: 2017 joint urban remote sensing event (JURSE), 6-8 March 2017, pp 1-4. https://doi.org/10.1109/jurse.2017.7924554

Ridd MK (1995) Exploring a V-I-S (vegetation-impervious surface-soil) model for urban ecosystem analysis through remote-sensing-comparative anatomy for cities. Int J Remote Sens 16:2165-2185

Roberts DA, Quattrochi DA, Hulley GC, Hook SJ, Green RO (2012) Synergies between VSWIR and TIR data for the urban environment: an evaluation of the potential for the hyperspectral infrared imager (HyspIRI) decadal survey mission. Remote Sens Environ 117:83-101. https://doi.org/10.1016/j. rse.2011.07.021

Roessner S, Segl K, Heiden U, Kaufmann H (2001) Automated differentiation of urban surfaces based on airborne hyperspectral imagery. IEEE Trans Geosci Remote Sens 39:1525-1532

Rosentreter J, Hagensieker R, Okujeni A, Roscher R, Wagner PD, Waske B (2017) subpixel mapping of urban areas using EnMAP data and multioutput support vector regression. IEEE J Sel Top Appl Earth Obs Remote Sens 10:1938-1948. https://doi.org/10.1109/JSTARS.2017.2652726

Schiefer S, Hostert P, Damm A (2006) Correcting brightness gradients in hyperspectral data from urban areas. Remote Sens Environ 101:25-37

Segl K et al (2012) EeteS-The EnMAP End-to-End simulation tool. IEEE J Sel Top Appl Earth Obs Remote Sens 5:522-530. https://doi.org/10.1109/JSTARS.2012.2188994

Seto KC, Sanchez-Rodriguez R, Fragkias M (2010) The new geography of contemporary urbanization and the environment. Ann Rev Environ Resour 35:167-194. https://doi.org/10.1146/annurev-envir on-100809-125336

Singh A, Serbin SP, McNeil BE, Kingdon CC, Townsend PA (2015) Imaging spectroscopy algorithms for mapping canopy foliar chemical and morphological traits and their uncertainties. Ecol Appl 25:2180-2197

Small C (2001) Estimation of urban vegetation abundance by spectral mixture analysis. Int J Remote Sens 22:1305-1334

Small C (2003) High spatial resolution spectral mixture analysis of urban reflectance. Remote Sens Environ 88:170-186

Small C (2005) A global analysis of urban reflectance. Int J Remote Sens 26:661-681

Small C, Okujeni A, van der Linden S, Waske B (2018) 6.07-remote sensing of urban environments A2-Liang, Shunlin. In: Comprehensive remote sensing. Elsevier, Oxford, pp 96-127. https://doi. org/10.1016/B978-0-12-409548-9.10380-X

Stewart ID, Oke TR (2012) Local climate zones for urban temperature studies. Bull Am Meteorol Soc 93:1879-1900. https://doi.org/10.1175/bams-d-11-00019.1

Tan J et al (2010) The urban heat island and its impact on heat waves and human health in Shanghai. Int J Biometeorol 54:75-84. https://doi.org/10.1007/s00484-009-0256-X

Tigges J, Lakes T, Hostert P (2013) Urban vegetation classification: benefits of multitemporal RapidEye satellite data. Remote Sens Environ 136:66-75. https://doi.org/10.1016/j.rse.2013.05.001 
UN (2018) World urbanization prospects. The 2018 revision. https://esa.un.org/unpd/wup/Publications/Files /WUP2018-KeyFacts.pdf. Accessed 7 June 2018

UN-Habitat (2010) State of the world's cities 2010/2011 - cities for all: bridging the urban divide state of the world's cities reports. UN-Habitat, $224 \mathrm{p}$

van der Linden S, Hostert P (2009) The influence of urban structures on impervious surface maps from airborne hyperspectral data. Remote Sens Environ 113:2298-2305. https://doi.org/10.1016/j. rse.2009.06.004

van der Linden S, Janz A, Waske B, Eiden M, Hostert P (2007) Classifying segmented hyperspectral data from a heterogeneous urban environment using support vector machines. J Appl Remote Sens 1:013543

van der Meer FD et al (2012) Multi- and hyperspectral geologic remote sensing: A review. Int J Appl Earth Obs Geoinf 14:112-128. https://doi.org/10.1016/j.jag.2011.08.002

Van Wittenberghe S et al (2013) Upward and downward solar-induced chlorophyll fluorescence yield indices of four tree species as indicators of traffic pollution in Valencia. Environ Pollut 173:29-37. https:// doi.org/10.1016/j.envpol.2012.10.003

Voogt JA, Oke TR (2003) Thermal remote sensing of urban climates. Remote Sens Environ 86:370-384. https://doi.org/10.1016/S0034-4257(03)00079-8

Weng QH (2001) Modeling urban growth effects on surface runoff with the integration of remote sensing and GIS. Environ Manag 28:737-748

Weng Q, Hu X, Lu D (2008) Extracting impervious surfaces from medium spatial resolution multispectral and hyperspectral imagery: a comparison. Int J Remote Sens 29:3209-3232. https://doi. org/10.1080/01431160701469024

Wetherley EB, Roberts DA, McFadden JP (2017) Mapping spectrally similar urban materials at sub-pixel scales. Remote Sens Environ 195:170-183. https://doi.org/10.1016/j.rse.2017.04.013

Wirion C, Bauwens W, Verbeiren B (2017) Location- and time-specific hydrological simulations with multiresolution remote sensing data in urban areas. Remote Sens 9:645

Wu CS, Murray AT (2003) Estimating impervious surface distribution by spectral mixture analysis. Remote Sens Environ 84:493-505

Yokoya N, Chan J, Segl K (2016) Potential of resolution-enhanced hyperspectral data for mineral mapping using simulated EnMAP and Sentinel-2 images. Remote Sens 8:172

Zhou GQ, Chen WR, Kelmelis JA, Zhang DY (2005) A comprehensive study on urban true orthorectification. IEEE Trans Geosci Remote Sens 43:2138-2147

Zhu Z, Woodcock CE, Rogan J, Kellndorfer J (2012) Assessment of spectral, polarimetric, temporal, and spatial dimensions for urban and peri-urban land cover classification using Landsat and SAR data. Remote Sens Environ 117:72-82. https://doi.org/10.1016/j.rse.2011.07.020 